\title{
ESPAÇOS LIVRES E ESPACIALIDADES DA ESFERA DE VIDA PÚBLICA: UMA PROPOSIÇÃO CONCEITUAL PARA O ESTUDO DE SISTEMAS DE ESPAÇOS LIVRES URBANOS NO PAÍS
}

\author{
OPEN SPACES AND PUBLIC LIFE SPATIALITIES: A CONCEPTUAL PROPOSAL TO THE \\ RESEARCH OF THE COUNTRY'S URBAN OPEN SPACES SYSTEM
}

\begin{abstract}
Akemi Hijioka, Antonio Augusto Delfim da Silva Santos, Danielle Klintowitz, Eugenio Fernandes Queiroga, Fábio Robba, Fany Cutcher Galender, Helena Napoleon Degreas, Karla Lopez Blanco Alvarez, Kim Ordonha Cyrillo, Lucila Lopes Cerqueira, Maria Helena de F. Preto, Naiara Luchini de Assis Kaimoti, Natália Pimenta Mambrini, Paulo Barreiros de Oliveira, Roberto Sakamoto Rezende de Souza, Silvio Soares Macedo, Sirlene Barbosa de Brito, Ulisses Dias Cambraia Sardão e Vanderli Custódio
\end{abstract}

\section{RESUMO}

Este texto é o resultado da primeira etapa de trabalhos da fase número quatro do Projeto de pesquisa Quapá - Quadro do Paisagismo no Brasil, em desenvolvimento desde 1994 no Laboratório da Paisagem da FAUUSP, e que se voltará para o estudo teórico e metodológico dos sistemas de espaços livres na cidade brasileira, tendo como foco um conjunto das principais cidades de médio e grande porte do país. São apresentados conceitos que nortearão o novo processo de pesquisa, destacando-se os de espaço livre, sistema de espaços livres e áreas verdes.

Palavras-chave: Espaço, paisagem, sistema de espaços livres, espacialidades.

\begin{abstract}
This paper is the result of the first part of the newest stage of projeto Quapá - Quadro do Paisagismo no Brasil in developing at FAUUSP. Nowadays the main subject of the research is the discussion of the adequate concepts to the open and green spaces in a brazilian urban reality and to investigate how it has been its development in the main brazilian cities.
\end{abstract}

Key words: Space, landscape, open spaces system, spatial practices.

\section{Introdução}

Na cidade brasileira contemporânea são cada vez maiores as demandas por espaços livres, em especial aqueles destinados ao lazer, recreação, conservação e preservação. Percebe-se alguma preocupação com o projeto e manutenção dos espaços livres de circulação e acesso, como ruas e avenidas, enquanto o tratamento de praças, parques e outros espaços livres de edificação são deixados em segundo plano pelas diversas gestões municipais, responsáveis pela normalização, fiscalização, produção e gestão de grande parcela do sistema de espaços livres urbanos.

Paralelamente, existe uma grande imprecisão na conceituação do termo espaço que livre, freqüentemente confundido com a idéia de área verde, que, por sua vez, se sobrepõe ao conceito de espaço verde e assim por diante. Por outro lado, existe uma flagrante demanda por novos espaços livres na cidade brasileira, decorrente do expressivo processo de urbanização ocorrido, sobretudo, na segunda metade do século XX. Tais demandas foram parcialmente atendidas, e

116 quando o são, concentram-se principalmente nas áreas destinadas às elites e às classes médias. Apenas nas três últimas décadas nota-se alguma preocupação do Poder Público de se voltar efetivamente para as camadas mais pobres e mesmo para as classes médias, devido ao real peso político que adquirem devido ao seu potencial de votos. 
No cotidiano administrativo é comum a adoção do conceito área verde como um padrão de qualidade urbana e esta é avaliada por índices genéricos de distribuição, verdadeiras mágicas estatísticas que de fato não medem e não mostram a concreta realidade do sistema de espaços livres de cada localidade. Minimizam o papel real do sistema de espaços livres privados na estruturação da totalidade do sistema de espaços livres urbanos, encobrindo eventuais atendimentos de demandas, especialmente nas áreas mais ricas. Estas são, de longe, juntamente com as áreas mais centrais, os trechos urbanos mais bem aquinhoados com equipamentos e espaços livres públicos, quaisquer que seja sua finalidade.

Por outro lado, devido à citada omissão do Estado na produção e gestão dos espaços públicos, tem sido natural e freqüente a expansão da iniciativa privada na constituição e gestão de tais espaços, em geral inseridos em áreas condominiais de acesso restrito a poucos. Ressalte-se ainda o amplo processo de dispersão urbana em andamento, em especial nas ultimas décadas em função da consolidação do veículo automotor como principal meio de transporte individual e coletivo no país. Este fato leva à criação de novas e diferenciadas demandas, que tornam anacrônicas idéias e conceitos de planejamento urbano e paisagístico então em voga.

A recente produção do sistema urbano de espaços livres pela ação privada é expressiva e envolve todas as camadas sociais. A falta de articulação entre as diversas propostas gera uma trama urbana individualizada e desconectada.

A cidade brasileira do ano 2006 se configura de diversas formas, com áreas centrais e seus bairros mais antigos compactos e contínuos; com extensas áreas lineares e descontínuas se estendendo ao longo de rodovias e vias de trânsito rápido; com manchas isoladas e esparsas de condomínios de alto e médio padrão e de bairros populares espalhados pelo território municipal.

Este é o quadro de um processo de estruturação urbana cujo perfil paisagístico e ambiental deverá ser reavaliado. Os conceitos apresentados neste artigo, foram adotados de um modo preliminar, de modo a permitir o estabelecimento de uma primeira carta de parâmetros de discussão desta realidade, de modo que se possa criar uma base conceitual própria nacional sobre o assunto, até então fortemente balizados por padrões anglo-saxônicos, visivelmente pouco adequados a uma realidade latina e de um país com características peculiares e variadas como o Brasil.

\section{Conceitos}

Para atingirmos uma fundamentação teórica que permita que o grupo de pesquisa, de âmbito nacional, possa compartilhar de uma mesma base, apresentamos o resultado de alguns pressupostos conceituais que foram debatidos pela equipe. Os conceitos estão aqui colocados de modo a se estabelecer uma primeira toca de idéias com todos que queiram estabelecer parcerias com processo de estudo por nós deflagrado, se pretendendo a partir da sua discussão e posterior desenvolvimento de fato estabelecer referencias, apresentamos então os seguintes conceitos: espaço, paisagem, espaço livre, sistema de espaços livres.

\section{Espaço}

O termo - espaço - possui significados distintos conforme a área de atuação. Ele não é apenas objeto de interesse da Arquitetura, mas também da Geografia, da Psicologia, da Filosofia e de outras áreas do conhecimento.

Como os geógrafos, os arquitetos entendem o espaço como uma totalidade. O espaço é um conjunto indissociável de sistemas de objetos e sistemas de ações (SANTOS, 1996, p.19)'. A dimensão propositiva do olhar do arquiteto, porém, induz a uma fragmentação dessa totalidade em subespaços e à sua conseqüente adjetivação e/ou especificação (espaço urbano, espaço livre, espaço verde, etc.). 
Os subespaços são categorizados, recebendo mais qualificações, de modo a que se diferenciem de outros para atender às especificidades e diferenças de escala dessa dimensão propositiva.

Na linguagem formal da arquitetura, paisagismo e urbanismo, utiliza-se o termo espaço adido de um adjetivo para definir o que seria um fragmento do espaço como totalidade (um subespaço). Por exemplo, o subespaço urbano é um fragmento do espaço que normalmente é chamado de espaço urbano e dentro deste subespaço existirão outros diversos subespaços ou sub-subespaços que são tratados simplesmente como espaço, mais a sua qualificação (espaço livre urbano, espaço edificado, etc.)

O espaço como um sistema de objetos e de ações, é uma instância social, pois é produto da natureza transformada pela sociedade. É o resultado da sociedade, ele se concretiza através de um processo histórico e, portanto, dinâmico.

O espaço pode ser apreendido de diferentes maneiras conforme a percepção de quem o capta (materialização e percepção). Pode ser identificado conforme o aspecto plástico, estético, cultural, material, porém a sua materialidade se expressa de maneira única e essa será vivenciada de maneiras diversas por cada ser.

O conceito de espaço está ligado à idéia de totalidade e a dinâmica do presente, podendo ser estudado a partir de categorias, tais como, função, estrutura, processo, em diferentes níveis de articulação.

\section{Paisagem}

A paisagem é um recorte do espaço, ou seja, é uma categoria interna da totalidade. Segundo Macedo, "a paisagem pode ser considerada como um produto e como um sistema. Como um produto porque resulta de um processo social de ocupação e gestão de determinado território. Como um sistema, na medida em que, a partir de qualquer ação sobre ela impressa, com certeza haverá uma reação correspondente, que equivale ao surgimento de uma alteração morfológica parcial ou total" 2 (MACEDO, 1999, p. 11).

Assim, esses "produtos e sistemas" nascem do espaço apreendido e vivenciado e podem ser percebidos diferentemente conforme os padrões culturais presentes nos diversos grupos sociais. A paisagem, portanto, depende de uma dimensão perceptiva, mas tem, ao mesmo tempo, uma materialidade efetiva, vinculada a uma dimensão temporal. Desse modo, ela é a acumulação dinâmica de produtos de processos sociais e/ou naturais que resulta em uma fisionomia percebida pelo observador em um dado instante.

Os nossos sentidos, que permitem ações de reconhecimento e estranhamento, possibilitam muitas vezes a descoberta do novo. $O$ novo percebido no cotidiano pode ser identificado como fragmentos de paisagem ou unidades de paisagem.

O recorte de estudo de uma paisagem é definido de acordo com critérios estabelecidos, podendo ser um parque, uma cidade, um vale ou uma bacia hidrográfica.

Desse modo, concordamos com Magnoli quando define a paisagem como "conformação, configuração e ação" ${ }^{3}$ (MAGNOLI, 1982).

\section{Espaços livres de edificação}

A estrutura espacial da cidade é composta por duas categorias de sub-espaços: os espaços edi118 ficados e os espaços livres de edificação. Segundo Magnoli: "o Espaço Livre é todo espaço não ocupado por um volume edificado (espaço-solo, espaço-água, espaço-luz) ao redor das edificações e que as pessoas têm acesso", portanto o que define a diferença entre um espaço edificado e um espaço livre de edificação é a ausência de estruturas edificadas que configurem recintos ou 

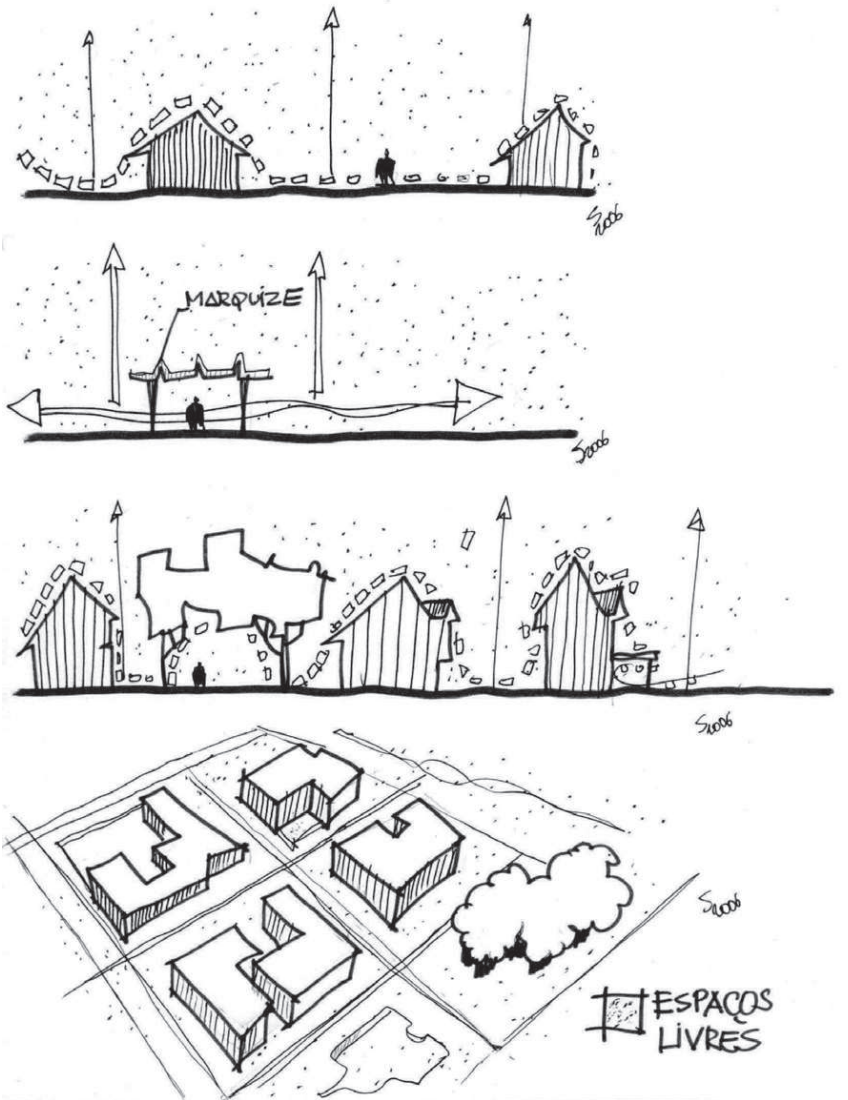

Figura 1: Espaços livres de edificações
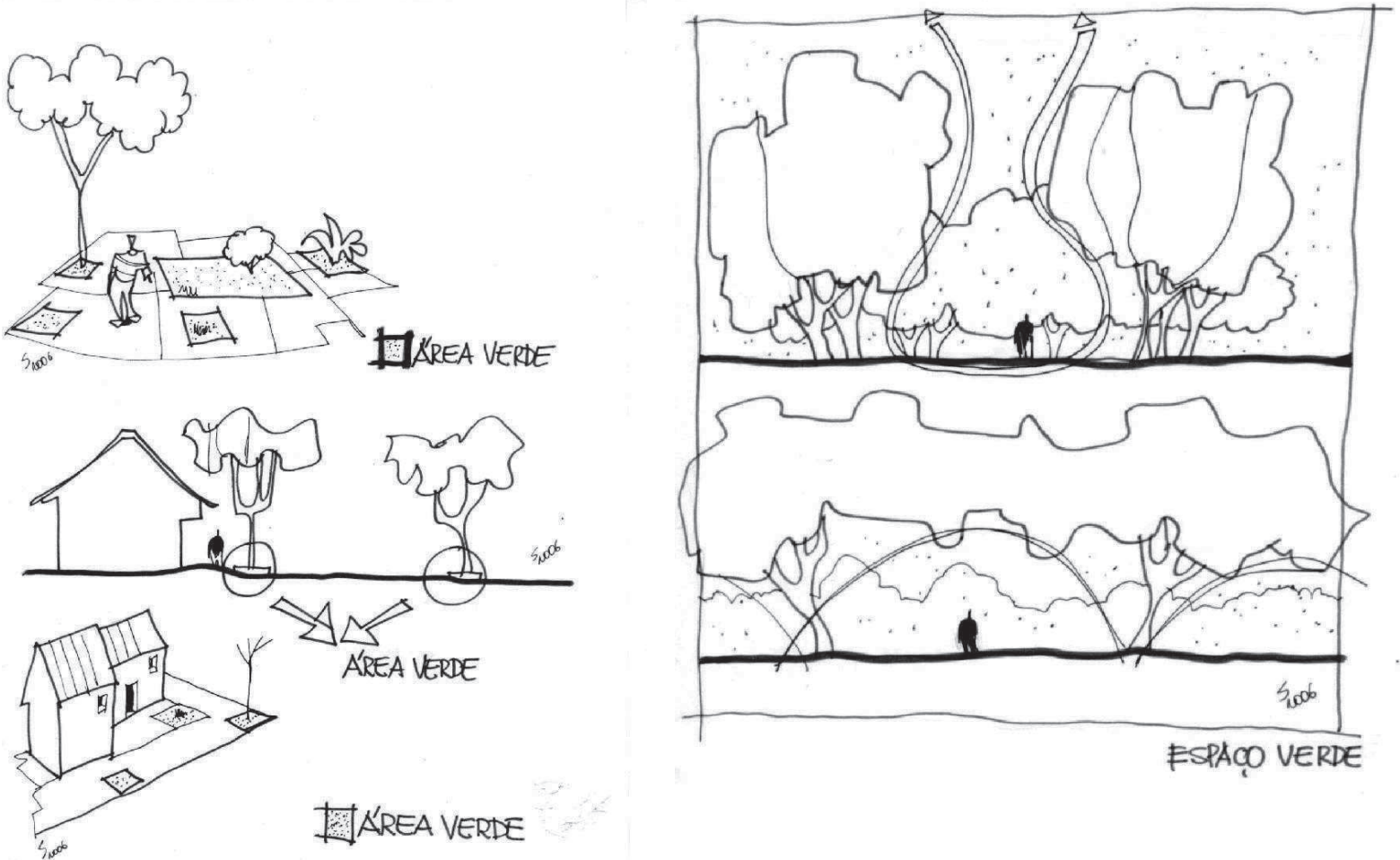

Figura 2: Área verde

Figura 3: Espaço verde ambientes cobertos e fechados, isto é, a ausência de paredes e tetos (MAGNOLI, 1982) . Assim, espaço livre é todo espaço não contido dentro de um invólucro.

Os espaços livres de edificação podem ser divididos em diferentes tipos tais como: as ruas, os quintais, os pátios, as calçadas, os terrenos, os parques e as praças, além de outros tantos por onde as pessoas fluem no seu dia-a-dia.

A articulação entre espaços livres e edificados configura e qualifica a forma urbana, organizando seus diversos tecidos.

O espaço livre normalmente está associado às áreas verdes na cidade e aos jardins urbanos. No entanto, sua definição o qualifica apenas quanto a sua condição de não confinamento, podendo eventualmente ser agregados outros adjetivos. $\bigcirc$ espaço livre de edificação pode ser "verde" (com vegetação), pode ser árido, poder ser alagado e assim por diante. 
A idéia de área verde é freqüentemente utilizada por arquitetos, urbanistas, paisagistas, geógrafos, etc. para qualificar ambiental e paisagisticamente as cidades, sendo freqüentemente associada a índices de origem duvidosa e claramente não comprovados em sua eficácia.

Área verde é toda e qualquer área que contenha vegetação situada em solo permeável. Essas áreas seriam uma categoria dos espaços livres de edificação. $O$ termo área verde se difere do espaço verde. Espaço verde é estruturado total e predominantemente por vegetação, e não necessariamente têm solo permeável.

Podemos citar como exemplo uma rua arborizada. $O$ seu volume plantado caracteriza um grande espaço verde, mas não uma área verde significativa, pois se encontra pouca área permeável e efetivamente plantada.

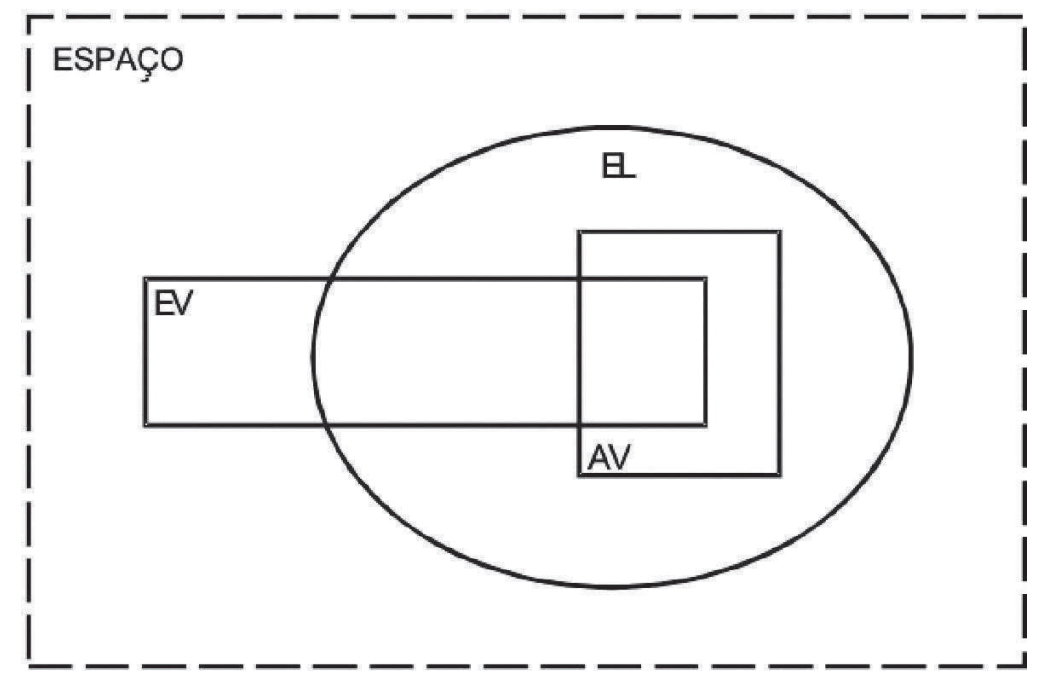

Espaço: totalidade EL: Espaço livre de edificação (ex: área sob um pergolado, terraço ao ar livre).

EV: Espaço verde (ex: jardim sobre laje, rua arborizada). AV: Área verde (ex: extensa área gramada, bosque).

* Espaço verde que não é espaço livre (ex: jardim dentro de uma edificação).

Figura 4: Relação entre o espaço e seus componentes: espaço livre, espaço verde e área verde

\section{Espaço público}

O espaço público é aquele de propriedade pública e apropriação pública. Segundo Hannah Arendt, o termo público significa, em primeiro lugar, que "tudo o que vem a público pode ser visto e ouvido por todos e tem a maior divulgação possível" (ARENDT, 2005, p. 59). Já a "esfera pública, enquanto mundo comum, reúne-nos na companhia uns dos outros e contudo evita que colidamos uns com outros, por assim dizer" (ARENDT, 2005, p. 62) . $^{\prime}$ O espaço público, portanto, é o lugar na cidade da prática de ações na esfera de vida pública.

entendimento do espaço público depende de três aspectos:

1. Questão fundiária - Segundo o Código Civil, entende-se por propriedade pública tudo aquilo que pertence à União, Estado, Município, Autarquias e Fundações públicas. Estes bens públicos são divididos em três categorias conforme sua destinação: bens de uso comum do povo, bens de uso especial e bens de uso dominial ou dominical.

Os bens de uso comum do povo podem ser usados sem qualquer autorização comunitária ou igualitária. É o caso de mares, rios, estradas, ruas e praças. Seu uso pode ser tanto gratuito ou oneroso (pedágios).

120 Os bens de uso especial só podem ser usados para os fins ao qual foram destinados, tais como: escolas, teatros, museus, hospitais, etc, podendo ainda, serem alugados com lucro.

Os bens de uso dominial ou dominical constituem o patrimônio, podem ser vendidos ou alienados, de acordo com as exigências e necessidades, mas com desafetação 5 . 
2. Apropriação - a esfera pública é determinada por um sistema de ações que the são próprias. Todo o espaço público é apropriado pela população, como por exemplo, as praças.

Entretanto a apropriação coletiva em determinados lugares de acesso restritivo, como por exemplo, os shopping centers, não pode ser entendida como espaço público, pois, tal ação se passa na esfera de vida social. Segundo Queiroga: "A esfera de vida social atravessa tanto o mundo do trabalho como do ócio, trata-se da vida em grupos sociais relativamente homogêneos, mais numerosos que os integrantes da vida privada e menos heterogêneos que os necessários para a caracterização da esfera como pública." Igualmente, ao que acontece nos clubes fechados, o sistema de ações desenvolvidos nestes espaços são limitados a determinados grupos sociais, caracterizando estes lugares como espacialidades sociais e não como espaços públicos. Do mesmo modo, em alguns espaços de propriedade privada pode se reconhecer práticas espaciais da esfera de vida pública, o que os caracteriza como espacialidades públicas (QUEIROGA, 2006).

Atualmente, dificilmente uma ação própria da esfera pública será partilhada por todos, e sim por vários grupos sociais diferentes; pode-se mesmo falar em "graus de publicidade" em função do maior ou menor número de grupos sociais envolvidos em determinado sistema de ações da esfera pública (QUEIROGA, 2006)7.

3. Acessibilidade - Identificamos diferentes graus de acessibilidade: físico, cultural, social, por normas e regras, etc. A acessibilidade cultural, por exemplo, depende dos códigos visuais do lugar. Não se pode confundir as restrições de acesso com as restrições de usos.

Como espaço público foi definido como de apropriação e propriedade pública, um parque cercado ou um zoológico, de propriedade do Estado, que requer pagamento, são considerados espaços públicos. O potencial de transparência, acessibilidade e visibilidade é maior no espaço público. Já, o termo "espaço coletivo", deve ser usado quando temos uma esfera de vida social fora de um espaço fundiário público, é uma territorialidade privada com uso social, ou seja, só existe sob domínio privado.

\section{Sistemas de espaços livres}

Sistema não é apenas um conjunto. Ele se define a partir do momento em que os elementos desse conjunto interagem, ou seja, quando eles estabelecem relações. Portanto, um sistema pode ser definido como uma estrutura que se organiza com base em conjuntos de unidades inter-relacionáveis por dois eixos básicos: o eixo das que podem ser agrupadas e classificadas pelas características semelhantes que possuem e o eixo das que se distribuem em dependência hierárquica ou arranjo funcional (HOUAISS, 2004) $)^{8}$.

Portanto, sistema é um complexo de elementos em interação com seus atributos próprios e estes atributos também interagem entre si. Qualquer totalidade ou todo organizado se constitui em um sistema, sendo suas relações fundamentais as constituintes de sua estrutura (ABBAGNANO, 1998, p. 909)9. A dimensão estrutural de um sistema não impede, entretanto, que ocorram transformações significativas no mesmo, tem-se assim a primazia do processo sobre a estrutura, do movimento dialético da história sobre os determinismos de qualquer ordem.

O sistema de espaços livres de uma cidade é o conjunto de todos os espaços livres de edificação existentes na malha urbana, sua distribuição, suas conexões e suas inter-relações funcionais e hierárquicas. Portanto, o sistema de espaços livres de uma cidade engloba todos es espaços livres de edificação, ou seja, abarca todos os vazios que envolvem os cheios (volumes edificados) e que estão conectados pela atmosfera e tem uma inter-relação de dependência e hierarquia. 
Por exemplo, um terreno baldio vizinho a um edifício, hierarquicamente é menos importante para o uso público do que a praça que está em frente, mas ao mesmo tempo permite que o sol e o vento cheguem às janelas do edifício. Qualquer mudança que ocorre nesse terreno terá conseqüências sobre o sistema de espaços livres como um todo, como por exemplo, se o terreno for ocupado por edifício maior dificultando a insolação de área do entorno ou se esse for totalmente arborizado criando um habitat para a fauna urbana.

A formação de um sistema de espaços livres pode ser totalmente projetada, parcialmente projetada ou decorrente da somatória das intervenções locais, isto é, a existência de um sistema de espaços livres não presume a existência de um planejamento e um controle eficaz sobre este.

Nas cidades brasileiras encontram-se alguns casos de sistemas de espaços livres parcialmente projetados, como, por exemplo, o sistema de parques de Curitiba e o conjunto de áreas reservadas para futuras intervenções no plano diretor da cidade de Porto Alegre. No entanto, na grande maioria das cidades o sistema é oriundo do modo de ocupação e da somatória das intervenções, o que reforça a condição de descontrole por parte do Poder Público sobre a construção da paisagem urbana.

"O sistema de espaços livres de São Paulo foi (mais) fruto do acaso e da somatória das ações dos empreendedores privados, que da ação premeditada por parte do poder público. Essa forma de produção do espaço urbano, dirigida, como é, por interesses privados, resultou num sistema de espaços livres, que se distancia das condições que propiciam melhor qualidade de vida para a população da cidade."10 (MENNEH, 2002, p. 200)

\section{Notas}

(1) SANTOS, Milton. A natureza do espaço: Técnica e tempo, razão e emoção. São Paulo: Hucitec, 1996, p. 19.

(2) MACEDO, Silvio. Quadro do Paisagismo no Brasil. São Paulo: FAUUSP, 1999, p. 11.

(3) MAGNOLI, Miranda M. E. M. Espaços livres e urbanização: Uma introdução a aspectos da paisagem metropolitana. 1982. Tese (Livre-docência) - Faculdade de Arquitetura e Urbanismo, Universidade de São Paulo, São Paulo, 1982.

(4) Idem nota 3.

(5) ARENDT, Hannah. A condição humana. 10. ed. Rio de Janeiro: Forence Universitária, 2005, p. 59 e 62.

(6) QUEIROGA, Eugênio. Espacialidades da esfera pública na urbanização contemporânea: $O$ caso da megalópole do Sudeste. In: MAGNOLI, Miranda; SOUZA, Saide. Discutindo a paisagem. São Carlos.

(7) Idem nota 6 .

(8) HOUAISS, Antonio. Dicionário Houaiss da língua portuguesa. Rio de Janeiro: Objetiva, 2004.

(9) ABBAGnANO, Nicola. Dicionário de filosofia. Trad. Alfredo Bosi. 2. ed. São Paulo: Martins Fontes, 1998.

(10) MENNEH, Márcia Halluli. O sistema de espaços livres públicos da cidade de São Paulo. 2002. Tese (Doutorado) - Faculdade de Arquitetura e Urbanismo, Universidade de São Paulo, São Paulo, 2002.

\section{Bibliografia}

ABBAGNANO, Nicola. Dicionário de filosofia. Traduçaõ de Alfredo Bosi. 2. ed. São Paulo: Martins Fontes, 1998.

ARENDT, Hannah. A condição humana. 10. ed. Rio de Janeiro: Forence Universitária, 2005.

HOUAISS, Antonio. Dicionário Houaiss da língua portuguesa. Rio de Janeiro: Objetiva, 2004.

MACEDO, Silvio. Quadro do Paisagismo no Brasil. São Paulo: FAUUSP, 1999.

MAGNOLI, Miranda M. E. M. Espaços livres e urbanização: Uma introdução a aspectos da paisagem metropolitana. 1982. Tese (Livre-docência) - Faculdade de Arquitetura e Urbanismo, Universidade de São Paulo, São Paulo, 1982. 
MENNEH, Márcia Halluli. O sistema de espaços livres públicos da cidade de São Paulo. 2002. Tese (Doutorado) - Faculdade de Arquitetura e Urbanismo, Universidade de São Paulo, São Paulo, 2002.

QUEIROGA, Eugênio. Espacialidades da esfera pública na urbanização contemporânea: O caso da megalópole do Sudeste. In: MAGNOLI, Miranda; SOUZA, Saide. Discutindo a paisagem. São Carlos, no prelo.

SANTOS, Milton. Espaço e método. São Paulo: Nobel, 1985.

A natureza do espaço: Técnica e tempo, razão e emoção. São Paulo: Hucitec, 1996.

YÁZIGI, Eduardo. O mundo das calçadas. São Paulo: Humanitas/FFLCH-USP, 2000. 